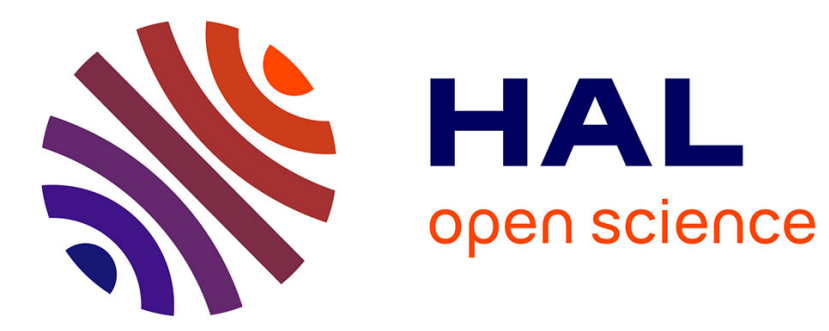

\title{
The Nexus between Oil price and Russia's Real Exchange rate: Better Paths via Unconditional vs Conditional Analysis
}

Jamal Bouoiyour, Refk Selmi, Aviral Kumar Tiwari, Muhammad Shahbaz

\section{- To cite this version:}

Jamal Bouoiyour, Refk Selmi, Aviral Kumar Tiwari, Muhammad Shahbaz. The Nexus between Oil price and Russia's Real Exchange rate: Better Paths via Unconditional vs Conditional Analysis. 2014. hal-01880335

\section{HAL Id: hal-01880335 \\ https://hal-univ-pau.archives-ouvertes.fr/hal-01880335}

Preprint submitted on 24 Sep 2018

HAL is a multi-disciplinary open access archive for the deposit and dissemination of scientific research documents, whether they are published or not. The documents may come from teaching and research institutions in France or abroad, or from public or private research centers.
L'archive ouverte pluridisciplinaire HAL, est destinée au dépôt et à la diffusion de documents scientifiques de niveau recherche, publiés ou non, émanant des établissements d'enseignement et de recherche français ou étrangers, des laboratoires publics ou privés. 


\section{n \\ (1)

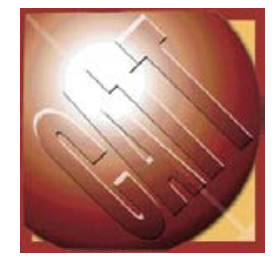

Centre d'Analyse Théorique et de Traitement des données économiques

CATT WP No. 4

September 2014

THE NEXUS BETWEEN OIL PRICE AND RUSSIA'S REAL EXCHANGE RATE: BETTER PATHS VIA UNCONDITIONAL VS CONDITIONAL ANALYSIS

Jamal BOUOIYOUR Refk SELMI Muhammad SHAHBAZ Aviral Kumar TIWARI 


\title{
The Nexus between Oil price and Russia's Real Exchange rate: Better Paths via Unconditional vs Conditional Analysis
}

\author{
Jamal BOUOIYOUR \\ CATT, University of Pau, France. \\ Email: jamal.bouoiyour@univ-pau.fr \\ Refk SELMI \\ ESC, Business School of Tunis, Tunisia. \\ Email: s.refk@yahoo.fr \\ Aviral Kumar TIWARI \\ IFHE-IBS Hyderabad, India. \\ E-mail: aviral.eco@gmail.com \\ Muhammad SHAHBAZ \\ COMSATS Institute of Information Technology, \\ Lahore, Pakistan. Email: shahbazmohd@live.com
}

\begin{abstract}
The present study deals with the nexus between oil price and Russia's real exchange rate along different econometric methods (ARDL bounds testing approach, wavelet coherency and frequency domain through Breitung and Candelon's (2006) technique). The obtained findings are highly suggestive of a sharp causal connection running from oil price to real exchange rate in lower frequencies. The reverse link is not supported. This implies that Russia should effectively tackle with short-run disturbances triggered by oil price and continue to decrease its great dependence on the energy sector via drastic and proactive measures. The economic and fiscal initiatives of Putin administration may help to better cope with sudden shocks, to reach weaker oil dependency and to create the confidence needed for economic recovery. While our research does not say much about the routes through which oil price may affect differently the real exchange rate, it clearly indicates the presence of shortterm nexus conditioning upon potential control variables including GDP, governmental revenues, terms of trade and productivity differential. The unconditional analysis appears as a meaningless exercise to find a clearer relationship between the focal variables.
\end{abstract}

Keywords: Oil price; Exchange rate; Unconditional analysis; Conditional analysis; Russia. 


\section{Introduction}

Since the 1973 oil crisis, the world has experienced several oil price jumps and declines. In particular, we wonder how the rise of oil prices affects movements of the dollar. As a result, the possible detrimental effects of excessive oil price fluctuations on real effective exchange rate still have no clear-cut answers despite the huge number of researches on the issue (Dibooglu (1996), Amano and van Norden (1998), Camarero and Tamarit (2002), Akram (2004), Chen and Chen (2007), Bénassy-Quéré et al. (2007), Narayan et al. (2008), Lizardo and Mollick (2010), Gosh (2011), Mansor (2011), Tiwari et al. (2013), Abulescu et al. (2013), Bouoiyour and Selmi (2014 a), among others). This increases the need to tackle properly and appropriately whether oil price may be considered as a potential source of real exchange rate volatility. .

The majority of post-Bretton Woods studies provide evidence that real exchange rate and real oil price are cointegrated and that oil prices may have been the dominant contributor of persistent shocks and sizeable volatility of real exchange rates (Krugman (1983) and Meese and Rogoff (1988)). There are various routes through which oil price may affect heavily real exchange rate, including fiscal flexibility (Zhou (1995) and Amano and van Norden (1998)), terms of trade (Coudert et al. 2008), productivity shocks (Bénassy-Quéré et al. 2007) and the cyclical behavior of international primary commodity prices (Benhmad (2012) and Bouoiyour and Selmi (2014 b)). Intuitively, because an excessive volatile behavior of exchange rate creates uncertainty in the development of macroeconomic policies an accurate investigation of the connection between real effective exchange rate and oil price fluctuations seems substantial for countries which have swapped their exchange regimes from fix to float. Given that the effectiveness of an exchange rate regime is measured through instability, the remarkably excessive fluctuations of oil prices have led to a huge amount of studies analyzing the nexus between the key variables. The empirical survey on the issue suggests the presence of an inconclusive and unclear relationship between oil price and real exchange rate variability. To gauge appropriately the exchange rate-oil price nexus, we attempt to conduct initially a through guidance of the main findings of previous studies. Indeed, the literature on the focal link has followed four main axes:

The first one presents the studies that assess the long-run interaction dynamic between real oil price and real effective exchange rate and figure out whether the reversal connection could be permanent or not. Accordingly, Chen and Chen (2007) and Bénassy et al. (2007) argue that there is a causal link between oil price and exchange rate running from oil price to real effective exchange rate and not vice versa. Nevertheless, Sadorsky (2000) and Zhang et al. (2008) support the reverse link.

The second strand of the literature on this subject attempts to assess empirically the short-run dynamics between changes in oil prices and those of real exchange rate (Narayan et al. (2008), Gosh (2011), Mansor (2011) and Selmi et al. (2012)). They propose an indicator that explains the real exchange rate uncertainty in accordance with fluctuations of oil price or the conditional variance between the two variables using generalized autoregressive conditional heteroskedasticity models. More recently and using copula-based GARCH model, Reboredo (2012) examined the co-movements between oil prices and exchange rate in the US 
economy. This research provides evidence that there is a dependence structure and a significant interdependence between oil price and US dollar exchange rate returns that change substantially within the periods in question.

Furthermore, several studies examine the nexus between oil price and real exchange rate in a linear framework (Dibooglu (1996) and Amano and van Norden (1998)). To distinguish the effects of increases and decreases of oil prices on exchange rates, some researches analyze the focal issue in a nonlinear fashion while trying to detect regimes at which one real exchange rate reacts differently to changes in oil price. For instance, Raymond and Rich (1997) use a Markov switching regime model to evaluate the impacts of rising and falling oil price trends on fluctuations in aggregate U.S. economic performance before and after World War II. At the same context, Akram (2004) explores the linkage between changes in oil prices and those of the exchange rate in Norway within a nonlinear framework. He shows that the strength of this relationship varies with the trends in oil prices and that Norway's exchange rate policy offers a firmer stance against appreciation pressures rather than depreciation ones.

Intuitively, recent studies have recognized that there are different time periods for decisions-making, whereas assessments are usually restricted to time domain or at least two time horizons, namely, the short-run and the long-run. Although most of the empirical researches have focused on the time domain nexus between exchange rate variability and oil price movements, few works on this field have paid attention to how this nexus evolves over time using discrete wavelet decomposition, continuous wavelets and frequency domain analysis (Shahbaz et al. (2013) and Tiwari et al. (2013) and Bouoiyour and Selmi (2014 a)). The majority of these studies considers the interdependence between each two time series without accounting for the possible interaction with other control variables, which may be ineffective. On the one hand, these methods may lead to confusing outcomes since the occurrence of noise cannot be heavily neglected, disrupting then the relationship under consideration. On the other hand, wavelet decomposition and the frequency domain causality are generally applied to assess respectively the multiple signals and the periodicity that happens over time. Moreover, when we consider only two variables, we generally fall on the problem of simple regression without control variable which is unable to capture appropriately proper results with regard to the focal nexus since it may distort the estimate. In that context, Aguiar-Conraria and Soares (2011) argue that the findings change intensely when we move from an analysis with two variables (unconditional assessment) to an investigation that considers more than two variables (conditional analysis). This highlights insightful evidence that the use of large-scale parameters of each two variables may yield to ambiguous and inconclusive outcomes in terms of the causal connection between oil price and the real exchange rate. To be effective, we need, therefore further investigation of the focal nexus. The contribution of the present study is to apply different models including ARDL bounds testing approach, unconditional cross-wavelet coherency and frequency causality versus conditional ones through various explanatory variables (GDP, governmental revenues, terms of trade and productivity differential) while trying to highlight new insights and to find better paths. 
Another contribution of this paper is related to the studied country. An analysis of Russian case may be interesting for at least four main reasons: Firstly, The fact that Russia is very dependent to the ups and down oil price movements can generate serious problems in terms of monetary and exchange rate policies. An increase in the energy commodity price on the world markets encourages more investment in the given sector, which in turn increases sectoral output. However, the need for more labor to produce more output in the energy sector causes an increase in wages across sectors. This leads necessarily to a drop in the competitiveness of the non-oil sector, implying a slowdown in exports. In that context, Egert (2005) argues that countries rich in natural resources and especially those with economic structures relying heavily on oil exports including Russia are usually good candidates for the Dutch disease. Secondly, Russia has experienced a particular evolution of its exchange regimes accompanied with a sharp energy policy evolution during the post-Soviet period (Rautava, 2004). Thirdly, Russian monetary authorities have different objectives determined stochastically over time that lead to evaluate frequently the interactive dynamic between the concerned macroeconomic time series. Lastly, the tendency of a currency to co-move with commodity prices, including oil price instability "the commodity-currency property" (Coudert et al. 2008) improve the need to be more attentive to oil shocks, sudden disturbances, speculative attacks and price cyclicality that characterize the energy market. All the above elements have reinforced our interest to a succinct description and a proper empirical investigation of the nexus between real effective exchange rate and oil price with special reference to an oil exporting country (i.e. Russia).

The remainder of the article proceeds as follows: We begin with a brief overview of exchange policy and oil price evolution in the Russian case (section 2). Then, we describe our data followed by methodology in section 3. Section 4 reports our main results and discusses them. Section 5 deals with some economic implications and offers concluding remarks.

\section{An overview of exchange policy and oil price evolution: Russian context}

Since the dismantlement of the Soviet Union, the Russian economy has experienced several events. As a result, Russia's exchange rate policy has passed through multiple regimes in order to better cope with external shocks. This research presents a succinct description of the Russian exchange rate development and oil price evolution.

The Russian oil stock is the seventh largest oil reserves in the world after Saudi Arabia, Venezuela, Iran, Iraq, Kuwait and UAE (Galkovskaya, 2010). Russia plays an important role as a supplier of energy in the world. In this country, oil exports account for almost 40\% of total country's exports. In the period from 1994 to 2009, the oil exports generated almost 50\% of export revenues and therefore Russian economy depends substantially on this sector, which increase almost continuously from 2000 to 2009 (Bouoiyour and Selmi, 2014 b). However, oil production declined in 2008 for the first time since 2000 to 2009 and then increases slightly in 2009 (statistical review of world energy, 
2010). Given these circumstances, Russia has played a major role in setting oil prices in the world market. It is therefore a "price maker".

Being a country highly dependent on energy's exports, Russia has to deal with sizable volatility in export earnings relating to commodity price developments -in particular oil price fluctuations- in international markets. As a response, the Russian monetary authorities have given greater preference to massive currency interventions (Merlevede et al. 2009). The question here is whether the adopted exchange rate policy seems effective to overcome oil shocks, the possible detrimental effects of the cyclical behavior of international commodity prices, speculative attacks and possible sudden disturbances that obviously characterize energy markets.

From 1992 to 1995, the real effective exchange rate is based on stabilization program. Despite this policy reform, the tension between price of oil and exchange rate stills. Granville and Mallick (2006) attribute this unexpected outcome to the authorities' use of macroeconomic policy as a direct instrument of social welfare provision. Then and particularly in 1995 M06, the Central Bank of Russia (CBR) has consistently limited the flexibility of the exchange rate by introducing the corridor system that allows the nominal exchange rate to move in a band within upper and lower limits. This exchange rate policy was instrumental in stabilizing the ruble and succeeded to mitigate the violent inflation that distinguish this period (Rautava, 2004). However, the financial crisis of 1998 affected heavily Russia's external position, i.e. the exchange rate uncertainty and the positive boost from rising energy prices put the Bank of Russia in an unfavorable position in managing monetary and exchange rate policies (Antczak, 2001). Besides, the aftermath of the Asian crisis puts the ruble under much greater pressure since Asia is one of the main trading partners of Russia1. To act appropriately to this event, the CBR began operating under a managed float exchange regime in order to keep the depreciation of its currency (Galkovskaya, 2011).

Furthermore, the ruble exhibited sharp instability from the end of 1998 to 2003, reflecting the excessive volatility of both the U.S. dollar and the euro, to which the ruble was pegged. The exchange market underwent September 2001 events, leading to a depreciation of ruble in relation to the U.S. dollar. Fortunately, the fiscal discipline, the strength of the oil price and the position of Russia as a price maker in the international oil market has succeeded to sustain budget surpluses since 2002. For the period through 2002 to 2003, the ruble remained tightly managed. However, in 2004, the Russian policy makers have chosen to adopt less restrictive capital control regulations, making a switch from an authorization-based system to flow control. As a result, the ruble has undergone steady upward pressure and the Bank of Russia intervened in the exchange market in order to contain the ruble's appreciation. Given this consequence, the Bank of Russia introduced a dual-currency basket from the end of 2005 in order to smooth the excessive volatility of ruble in relation to the major currencies. The basket composition was fixed at 55\% for the US dollar and 45\% for the euro. In 2008, the

\footnotetext{
${ }^{1}$ China, for example, is the second export partner (7.0\%) and import partner (14.0\%) for Russia. Japan is the fourth import partner (4.4\%) and Korea appears as the seventh import partner (3.8\%). For details about the main trade partners of Russia, we can refer to : http://atlas.media.mit.edu/profile/country/rus/
} 
current economic crisis has led to remarkable decline in oil prices affecting significantly the current account balance putting again the ruble under downward pressure. In response, Russian monetary authorities changed the exchange rate policy focus towards moderating the ruble's depreciation. Additionally, the Central Bank of Russia has conducted large scale interventions in exchange markets in order to improve the economic adjustments (Beck and Barnard, 2009). There are also some studies showing that the Putin administration has succeeded, to some extent, to better cope with oil price shocks and the current economic crisis. More precisely, the political and economic stabilization brought by president Putin and the initiation of a number of proactive fiscal policy reforms reduced economic uncertainty and political risk, which created the confidence obviously needed for economic recovery (Merlevede et al., 2009). From the second quarter 2009, the great flexibility of nominal effective exchange rate lets the CBR to change its interest rate policy. During this period, the interventions have steadily decreased, allowing monetary policy to focus squarely on inflation. This has helped to reduce the volatile behavior of ruble and has strengthened the interest rate channel policy transmission mechanism.

Figure-1 confirms the above descriptions. It is well seen that both oil price and real effective exchange rate have exhibited a great instability over the period 1995-2009. The graphs display the evolution of real exchange rate and oil price as well as their returns over the period in question. The crisis of Russia in 1998 proved to be a "purifying event" (Merlevede et al. 2009) since the real exchange rate sharply decreased from 1999. The oil price increased rapidly from this last date. As largest oil producer and second largest oil exporter of the world, Russia should benefit from the gradually observed increase of the price of crude oil. This does not mean that this economy is not vulnerable to oil price shocks. There are clearly periods of small fluctuations (for example 2002-2004 and 2006-2007) and periods of large fluctuations (for example 1997-1999). These observations reinforce the utmost importance of studying the frequency causal relationship between the two considered variables in order to effectively elucidate the understanding of practitioners and help Russian authorities in their decisions making and policy formulation.

Figure-1: The evolution of real exchange rate and oil prices

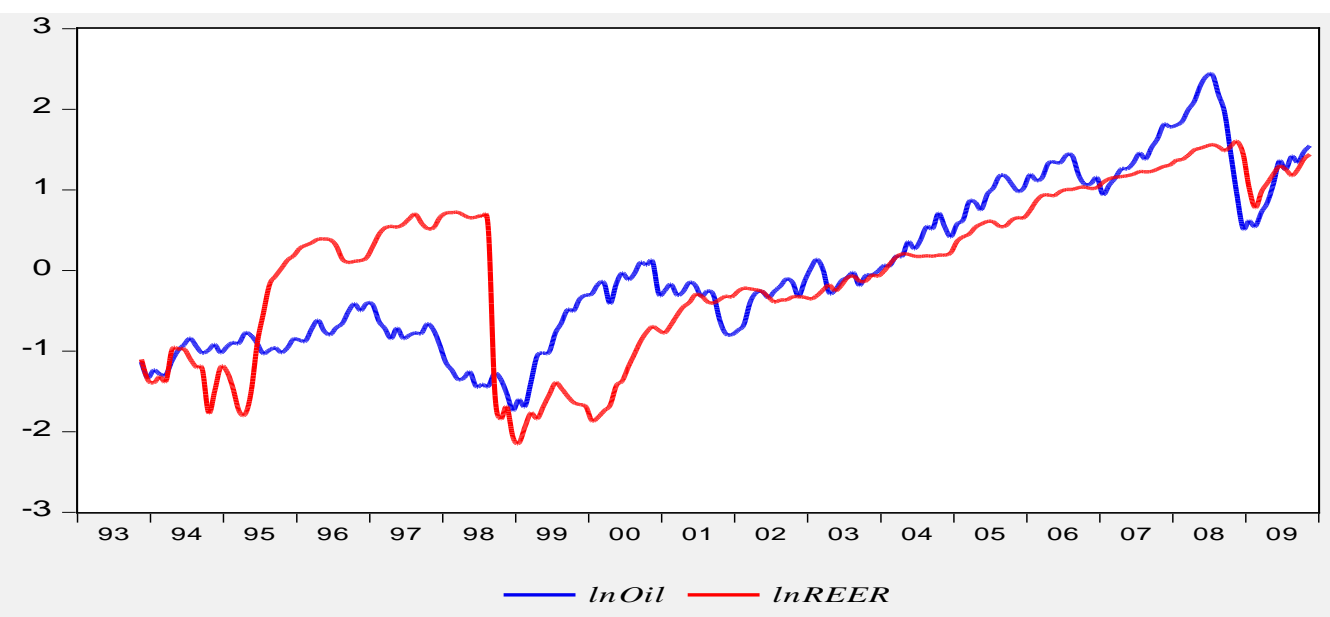

Notes: InOil: the logarithm of oil price; InREER: the logarithm of real effective exchange rate. 


\section{Analytical and Methodological framework}

\subsection{Analytical methodology}

In this article, we aim at better capturing the nexus between oil price and real exchange rate by paying particular attention to the evolution of this connection over time and at different frequencies unconditionally and conditioning upon GDP, governmental revenues, terms of trade and productivity differential. These additional control variables have been selected based on the following procedure.

In present real exchange rate model, Meese and Rogoff (1988) has linked real exchange rate to real interest rate differential while trying to mitigate problems related to monetary models. The real exchange rate $\left(R E E R_{t}\right)$ is defined as follows:

$$
\operatorname{REER}_{t}=e_{\mathrm{t}}+p_{\mathrm{t}}-p_{t}^{*}
$$

where $e_{t}$ : the price of a unit of foreign currency in terms of domestic currency; $p_{t}$ : the logarithm of domestic price; $p_{t}^{*}$ : the logarithm of foreign price.

Suppose that traded and non-traded goods are produced in the home and foreign countries, respectively.

$$
\begin{aligned}
& p_{t}=\alpha p_{t}^{T}+(1-\alpha) p_{t}^{N T} \\
& p_{t}^{*}=\alpha^{*} p_{t}^{T^{*}}+\left(1-\alpha^{*}\right) p_{t}^{N T^{*}}
\end{aligned}
$$

where $p_{t}^{T}\left(p_{t}^{T^{*}}\right)$ and $p_{t}^{N T}\left(p_{t}^{N T^{*}}\right)$ : the prices of traded and non-traded goods in the home and foreign countries; $\alpha$ and $\alpha^{*}$ : weights associated to the expenditure shares on traded goods for the home and foreign countries.

The real exchange rate can be expressed then as follows:

$$
\operatorname{REER}_{t}=\left(e_{t}+p_{t}^{T}-p_{t}^{T^{*}}\right)+(1-\alpha)\left(p_{t}^{T}-p_{t}^{N T}\right)-\left(1-\alpha^{*}\right)\left(p_{t}^{T^{*}}-p_{t}^{N T^{*}}\right)
$$

Thereafter, McDonald (1998) follows his proposal by dividing the real exchange rate fundamentals into various components, including essentially the real oil price as a potential source of real exchange rate variability; the effect of oil price shock depends substantially on the source of oil price fluctuations. A positive oil shock depends substantially on the source of oil price fluctuations. Theoretically, a positive oil shock may prompt a real exchange rate appreciation (depreciation) in oil exporters (importers). Several researches have provided that there are various factors that may attenuate the power of this link or more accurately the possible detrimental effects of oil shocks on real exchange rate, including economic growth, governmental revenues, terms of trade and productivity differential (Corden and Neary (1982), Chen and Rogoff (2003), Cashin et al. (2004), Tokarick (2008), among others). The equation that links real exchange rate with real oil prices and its further determinants may be expressed as follows: 


$$
R E E R_{t}=f(\text { Oil, gdp, gov, te, prod })
$$

where gdp: the growth of output; prod: the difference between the domestic and the foreign productivity; gov: the governmental revenues; Oil: the real price of oil; te: the terms of trade .

-The economic growth ( $g d p)$ : The GDP has been considered in some studies as the main determinant of the dynamic interaction between oil price and real exchange rate (Rautava, 2004). Conventional wisdom shows that an increase in oil price reduces the economic growth in oil importers and enhances it in oil exporting countries. In our case of study (Russian case), this evidence is not absolutely observed, especially when we clearly see that the oil price has increased remarkably in 2006 compared with 2005 (for example). The oil price expands by 1.62 per cent in 2005 and 1.87 per cent in 2006. ${ }^{2}$ This implies that oil price may be a significant contributor of economic growth in some economies, while it may possibly explain only partially the changes in the growth of GDP in other ones. This highlights -to some extent- that oil price may affect significantly the real exchange rate in both oil importers and exporters but slightly through the economic growth.

-The governmental revenues (gov): The oil price may be able to lead to great appreciations of real exchange rate via the governmental revenues. The latter can yield to the Dutch disease phenomenon (Corden and Neary, 1982).

-Terms of trade (te): The terms of trade show the interaction between export and import prices. It is therefore closely linked to the international commodity prices and their cyclical behavior. A positive shock in terms of trade may heavily increase the price of the non-traded products and then the real exchange rate (Camarero and Tamarit, 2002). The latter is the relative price of a basket of traded and non-traded goods between the domestic and the foreign country.

-The productivity differential (prod): The oil price may affect the real exchange rate via the productivity differential between the traded and non-traded good sectors. Accordingly, Tokarick (2008) argues that as the productivity is a potential source of terms of trade, it can reinforce the impact of terms of trade on the interconnection between oil price and the real exchange rate.

For empirical purpose, we have collected quarterly frequency data on oil prices and real effective exchange rate over the period of 1995q1-2009q4. The exchange rate is proxies by real effective exchange rate and collected from international financial statistics (CD-ROM, 2012). The crude oil price variable is expressed in real terms, i.e. deflated by U.S. consumer price index following Faria et al. (2009). The data on crude oil prices are the spot prices and collected from the U.S. Department of Energy: Energy Information Administration. The data on GDP, governmental expenditure revenues, terms of trade and productivity differential are available at Econstats $^{\mathrm{TM}}$.

\footnotetext{
${ }^{2}$ For more details, you can refer to the following link: http://www.thehindubusinessline.com/features/investment-world/macro-view/do-oil-prices-affect-real-gdpgrowth/article3459463.ece
} 


\subsection{Motivation and Introduction to Methodology}

Existing economic literature provides various studies applying various approaches to appropriately investigate the relationship between oil prices and exchange rate change and to reach a robust conclusion. Despite the large strand of literature on this issue, it is striking to note that the researchers have not paid proper attention to frequency transformations when examining the nexus between the two variables under consideration.

The majority of the previous studies use OLS, VECM and VAR methods to assess the focal relationship. These techniques were largely criticized for their perceived lack of robustness (Bouoiyour and Selmi, 2014 c), highlighting the importance of the use of more parsimonious methods. While econometric modeling often focuses on average, it seems more fruitful to assess the considered nexus under different and well-defined time horizons. We try in this research to apply different methods which are able to investigate the oil price-real exchange rate nexus under different time scales and to see whether there is substantial to account for nonlinearity when assessing this link.

Importantly, the use of various techniques may have different implications and provide conceptual background for the adequate econometric methods at an economic level in relation particularly to the focal issue with special reference to Russian case. To this end, we apply dynamic method (ARDL bounds testing approach), wavelet coherency and frequency domain. It will be important here to mention that the results of ARDL bounds testing approach may be vulnerable since this technique seems unable to detect possible structural breaks stemming in the variables. This drawback highlights the need to carry out more sophisticated methods that consider the time varying dynamics in the concerned series such as wavelet decomposition and frequency domain analysis. These last methods seem appropriate to depict signal transformations. The first one captures a signal changes over time-frequency, whereas a frequency-domain analysis indicates how the signal moves among given frequency bands. Basically, the time scale is the ability to highlight precisely when a variation happens by identifying specific time horizons. Wavelet transform represents an engineering tool for multi-resolution decomposition of signals that has attracted serious attention from several economists. From a computational point of view, it evaluates the time scale details of data whose spectral content varies over time (non-stationary series). There are no one-reached wavelet package for accurately assessing two time series together (for analyzing if regions in time-frequency space have a consistent phase relationship and thus are highly suggestive of a causality connection between oil price and the real exchange rate). Nevertheless, the frequency band is a component that allows us to determine effectively the degree of a certain variation. These econometric techniques enable to assess the causal relationships between the two key variables in the short, medium and long-run. Various researches have criticized the unconditional causality or the causality between the two series without accounting for other control variables that may have great influence on the studied linkage. When we consider only two series in the empirical investigation, it will be difficult to reach robust and unambiguous results with regard to the relationship in question since it may distort the estimate. This heavily indicates the great importance of deeper analysis of a causal relationship while 
accounting for additional variables that may play determinant roles in explaining the focal linkage.

\subsubsection{Unconditional versus conditional causality}

Considering $X$ and $Y$ as variables of interest and $Z$ as the conditional variable, the bivariate equation that allow us to rely the focal variables may be expressed as follows:

$$
\begin{aligned}
& X_{t}=\sum_{i=1}^{\infty} a_{0 i} X_{t-1}+\sum_{i=1}^{\infty} b_{0 i} Z_{t-i}+\varepsilon_{0 t} \\
& Z_{t}=\sum_{i=1}^{\infty} a_{1 i} X_{t-1}+\sum_{i=1}^{\infty} b_{1 i} Z_{t-i}+\mu_{0 t}
\end{aligned}
$$

where $\varepsilon_{0 t}$ and $\mu_{0 t}$ are independent and identically distributed with zero mean and variancecovariance matrix written as follows:

$$
\sum 1=\left(\begin{array}{l}
\sum \varepsilon_{0} \sum \varepsilon, \mu_{0} \\
\sum \mu_{a}, \varepsilon_{0} \sum \mu_{0}
\end{array}\right)
$$

(8)

$$
\begin{aligned}
& Y_{t}=\sum_{i=1}^{\infty} c_{0 i} Y_{t-1}+\sum_{i=1}^{\infty} d_{0 i} Z_{t-i}+v_{0 t} \\
& Z_{t}=\sum_{i=1}^{\infty} c_{1 i} Y_{t-1}+\sum_{i=1}^{\infty} d_{1 i} Z_{t-i}+\mu_{1 t}
\end{aligned}
$$

where $v_{0 t}$ and $\mu_{1 t}$ are independent and identically distributed with zero mean and variancecovariance matrix written as follows:

$$
\sum 2=\left(\begin{array}{l}
\sum v_{0} \sum v_{\grave{a}}, \mu_{1} \\
\sum \mu_{1}, v_{0} \sum \mu_{1}
\end{array}\right)
$$

Then, we can explore the link that runs from $X$ to $Y$ and inversely by accounting for the conditional variable by estimating trivariate equations expressed as follows:

$$
\begin{aligned}
& X_{t}=\sum_{i=1}^{\infty} \alpha_{1 i} X_{t-1}+\sum \beta_{1 i} Y_{t-i}+\sum_{i=1}^{\infty} \delta_{1 i} Z_{t-i}+\xi_{1 t} \\
& Y_{t}=\sum_{i=1}^{\infty} \alpha_{2 i} X_{t-i}+\sum_{i=1}^{\infty} \beta_{2 i} Y_{t-1}+\sum_{i=1}^{\infty} \delta_{2 i} Z_{t-i}+\varsigma_{1 t} \\
& Z_{t}=\sum_{i=1}^{\infty} \alpha_{3 i} X_{t-i}+\sum_{i=1}^{\infty} \beta_{i i} Y_{t-1}+\sum_{i=1}^{\infty} \delta_{3 i} Z_{t-i}+\eta_{1 t}
\end{aligned}
$$


Where $\xi_{1 t}$, $\varsigma_{1 t}$ and $\eta_{1 t}$ are independent and identically distributed with zero mean and variancecovariance matrix can be expressed as following:

$$
\sum 3=\left(\begin{array}{l}
\sum \xi_{1} \sum \xi_{1}, \varsigma_{1} \sum \xi_{1}, \eta_{1} \\
\sum \varsigma_{1}, \xi_{1} \sum \varsigma_{1} \sum \varsigma_{1}, \eta_{1} \\
\sum \eta_{1}, \xi_{1} \sum \eta_{1}, \varsigma_{1} \sum \eta_{1}
\end{array}\right)
$$

The causalities between $X$ and $Y$ conditionally to $Z$ are measured based on Geweke (1984)'s study by:

$$
F_{X \rightarrow Y / Z}=\ln \left[\frac{\sum \varepsilon_{0}}{\sum \xi_{1}}\right]
$$

and

$$
F_{Y \rightarrow X / Z}=\ln \left[\frac{\sum \mu_{0}}{\sum \varsigma_{1}}\right]
$$

The effect of the additional control variables on the nexus between $X$ and $Y$ may be detected properly from the above equations (16) and (17). If $Z$ has no influence on the studied

relationship, this implies that $\sum \varepsilon_{0}=\sum \xi_{1}$ and $\sum \mu_{0}=\sum \varsigma_{1}$ and therefore $F_{Y \rightarrow X / Z}$ and $F_{X \rightarrow Y / Z}$ are insignificant. However, if the conditional variables under consideration lead to a modification on the studied relationships, this means that $F_{Y \rightarrow X / Z}$ and $F_{X \rightarrow Y / Z}$ are significant.

Both unconditional and conditional causalities are estimated within wavelet coherency and phase difference and frequency domain framework. More precisely, we test in the first case the interconnection between oil price and real exchange rate (unconditional causality). Then, we re-explore the wavelet coherency and phase difference and the frequency causality test, but conditional to GDP, governmental revenues, terms of trade and productivity differential.

\subsubsection{Wavelet coherency and phase difference}

To properly capture the oil price-exchange rate nexus, the use of sophisticated models able to depict this relationship at different periods seems substantial for several reasons: (i) the excessive volatility of energy supply leads to changes in demand conditions and thereby to multiple energy price regimes; (ii) the massive currency intervention of Russian monetary authorities prompts us to account for nonlinearity; (iii) there may be a relationship between the time series under consideration at different frequencies such as oil price may act like a supply shock at lower and medium frequencies rather than long-run time frequencies (Naccache, 2011) and in resulting it affects frequently real effective exchange rate. For instance, the real effective exchange rate affects the oil prices following demand-effect in a short time scale (high frequency); (iv) considering low and high frequencies, we can 
differentiate between time horizons and help then policy makers in their decision as well defined time-horizons.

The wavelet analysis may provide a fresh look into the connection between oil price and Russia's oil price by evaluating it under different and precise time periods that may help policy makers to better cope with oil shocks. The wavelet coherency (WTC) and phase difference may allow us to effectively deal with the time-frequency dependencies between the two variables and to find thus significant coherence. Strictly speaking, these techniques have been applied quite successfully to large amount data and to extract the information relevant to nonlinear dynamic interaction between two variables (Tiwari et al. (2013) and Shahbacz et al. (2013)). They exhibit the time contribution of the different frequencies of the signal, to obtain then temporal frequency dependence. This can reflect structural changes that can happen over time.

Fourier analysis highlights an effective quantity, which is the coherence. It is defined as the square of the cross-spectrum normalized by the individual power spectra. This gives a quantity between 0 and 1 . Indeed, the Wavelet Coherency presents a high resemblance and a significant nexus between the key time series if coherence is near to 1 otherwise no relationship is found between the time series. It enables us to determine the cross-correlation between the two variables under consideration as a function of time and frequency. Given two time series $X$ and $Y$, one can define the complex wavelet coherency $\left(Q_{n}^{2}(s)\right)$ written as follows:

$$
Q_{n}^{2}(s)=\frac{S\left(s^{-1} W_{n}^{X Y}(s)\right)}{S\left(s^{-1}\left|W_{n}^{X}(s)\right|^{2}\right) \cdot S\left(s^{-1}\left|W_{n}^{Y}(s)\right|^{2}\right)},
$$

where smoothing operator is shown by $S$. It is a traditional correlation coefficient definition which is helpful in thinking of the Wavelet Coherence as a localized correlation coefficient following time frequency space.

This formula (18) can be expressed in polar form:

$$
Q_{n}^{2}(s)=\left|Q_{n}^{2}(s)\right| e^{i \phi_{x y}}
$$

The absolute value of complex wavelet coherence of two time series is named the wavelet coherency $\left(R_{n}^{2}(s)\right)$ and is denoted by:

$$
R_{n}^{2}(s)=\frac{\mid S\left(\left.s^{-1} W_{n}^{X Y}(s)\right|^{2}\right.}{s\left(s^{-1}\left|W_{n}^{X}(s)\right|^{2}\right) \cdot S\left(s^{-1}\left|W_{n}^{Y}(s)\right|^{2}\right)},
$$

According to Aguiar-Conraria et al. (2008, pp. 2872), the wavelet coherency is "the ratio of the cross-spectrum to the product of the spectrum of each series, and can be thought of as the local (both in time and frequency) correlation between two time-series". The equation (15) can be then re-written once smoothing operator is equal to 1 and smoothing operator $S$ as a convolution in time and scale: 


$$
S(W)=S_{\text {scale }}\left(S_{\text {time }}\left(W_{n}(s)\right)\right)
$$

where $S_{\text {scale }}$ denotes smoothing along the wavelet scale axis and $S_{\text {time }}$ indicates smoothing in time. The time of convolution is determined using Gaussian and scale convolution is done by regular window (Torrence and Compo, 1998). The functional form of smoothing power following Morlet wavelet is articulated as:

$$
\begin{aligned}
& \left.S_{\text {time }}(W)\right|_{s}=\left.\left(W_{n}(s) * c_{1}^{-t^{2} / 2 s^{2}}\right)\right|_{s} \\
& \left.S_{\text {scale }}(W)\right|_{n}=\left(\left.W_{n}(s) * c_{2} \Pi(0.6 s)\right|_{n}\right.
\end{aligned}
$$

where normalized constants are $c_{1}$ and $c_{2}$ while $\Pi$ denotes is the rectangle function. The scale de-correlation length for Morlet wavelet is empirical determined by 0.6. Practically, we determine convolutions directly, but the normalized coefficients are determined indirectly. The Monte Carlo simulation approach is used to assess the performance of wavelet coherency based on its theoretical distributions. It seems the most convenient in depicting the interdependence between two variables. Arguably, Aguiar-Conraria and Soares, (2011, p. 649) show that this technique is more appropriate than cross wavelet for two main reasons: "(1) the wavelet coherency has the advantage of being normalized by the power spectrum of the two time-series, and (2) that the wavelet cross spectrum can show strong peaks even for the realization of independent processes suggesting the possibility of spurious significance tests”.

The Monte Carlo methods are used to find statistical level of significance of the wavelet coherence, we need therefore to determine the confidence interval of the phase difference or the phase relation between two time series. Based on equation (19), the angle $\left(\phi_{X Y}=\phi_{X}-\phi_{Y}\right)$ is called the phase-difference. The main advantage of the phase difference is the fact that it cannot be affected by the smoothing choice (Aguiar-Conraria and Soares, 2011). It is written as following:

$$
\phi_{X Y}=\tan ^{-1} \frac{I\left\{W_{n}^{X Y}\right\}}{R\left\{W_{n}^{X Y}\right\}}, \phi_{X Y} \in[-\pi, \pi]
$$

The imaginary and real parts are indicated by $I$ and $R$ respectively, of the smooth power spectrum. The phase relationship between the two time series is characterized using path difference which is considered useful. The time series moves together with specified frequency if value of phase difference ranges to zero (Figure-2). The series move in phase if $\phi_{x, y} \in[0, \pi / 2]$ when series $\mathrm{x}$ is lead by $\mathrm{y}$ series. On contrary, if $\phi_{x, y} \in[-\pi / 2,0]$ then $\mathrm{x}$ is leading. We have an anti-phase relation (analogous to negative covariance) if we have a phase difference of $\pi$ or $(-\pi)$ meaning $\phi_{x, y} \in[-\pi / 2, \pi] \cup[-\pi, \pi / 2]$. If $\phi_{x, y} \in[\pi / 2, \pi]$ then $\mathrm{x}$ is leading, and the time series $y$ is leading if $\phi_{x, y} \in[-\pi,-\pi / 2]$. 


\section{Figure-2: Phase difference circle}

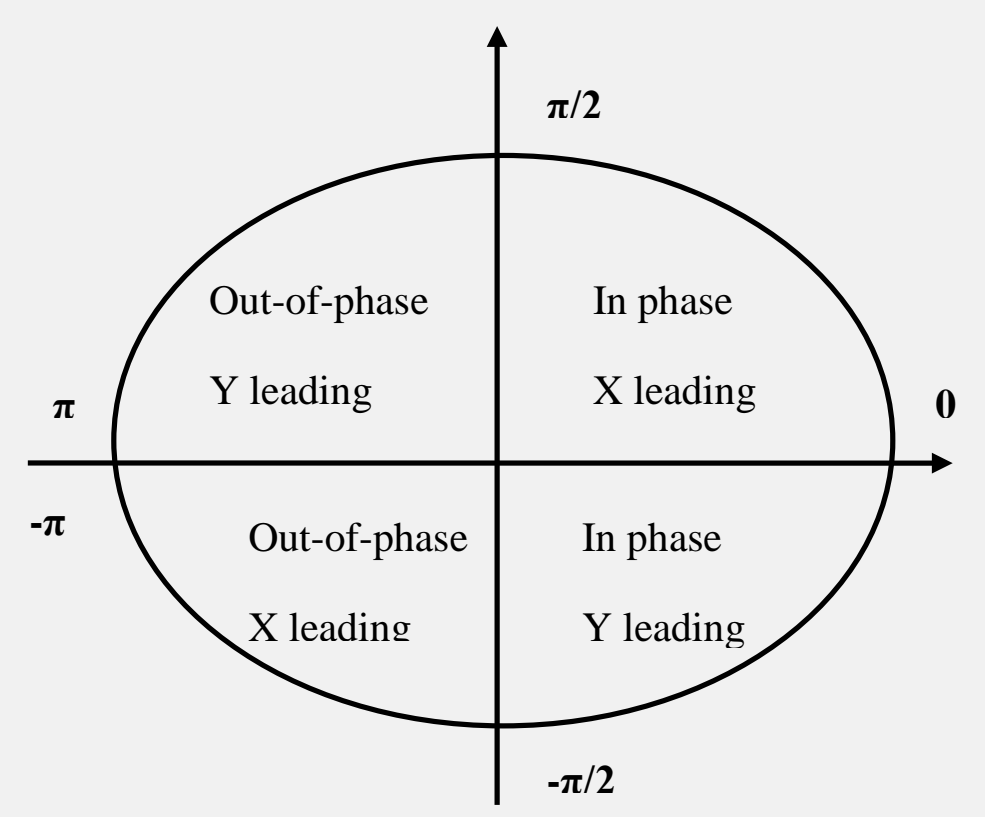

Note: For more details, we can refer to Aguiar-Conraria and Joana Soares (2011).

\subsubsection{Frequency domain approach}

The frequency domain analysis tests the causality between two variables as the Granger causality test. However, the latter seems not suited to distinguish between the short and long-run effects. To get a new look at the relationship and more proper analysis depending to frequency transformations, we apply a frequency domain Granger causality test (Breitung and Candelon, 2006). To this end, we begin by testing Granger causality “A variable $Y_{t}$ is said to Granger cause $X_{t}$, if $Y_{t}$ contains information to predict $X_{t}$ that is not available otherwise" (Lütkepohl 2005, pp.41). This method is restrictive since it cannot depict the concerned relationships at different horizons. It can be written as matrix notation:

$$
\Theta(L)=\left(\begin{array}{c}
X_{t} \\
Y_{t}
\end{array}\right)=\left(\begin{array}{l}
\theta_{11}(L) \theta_{12}(L) \\
\theta_{21}(L) \theta_{22}(L)
\end{array}\right)\left(\begin{array}{c}
X_{t} \\
Y_{t}
\end{array}\right)=\varepsilon_{t}
$$

$Y_{t}$ does not Granger cause $X_{t}$ if $\left(\Theta_{12}(L)=0\right)$, indicating that the past values of $Y_{t}$ seem not closely related to $X_{t}$. This can be tested by using an F-Test for the coefficients $\Theta_{12, i}$ for $\mathrm{i}=1 \ldots$ p. To overcome the Granger (1969)'s test restrictions, we use the frequency-domain Granger causality as a decomposition of the total spectral interdependence between variables into a sum of instantaneous and the bidirectional causality terms. Geweke (1984) argues that 
the causality test can be performed under different frequencies without loss of explanatory power, implying that causality measure $\left(F_{Y \rightarrow X}\right)$ can be decomposed as follows:

$$
F_{Y \rightarrow X}=\int_{0}^{\pi} f_{Y \rightarrow X}(\omega) d \omega
$$

Or with a consideration of conditional variable, meaning that causality measure $\left(F_{Y \rightarrow X}\right)$ can be decomposed as follows:

$$
F_{Y \rightarrow X / Z}=\int_{0}^{\pi} f_{Y \rightarrow X / Z}(\omega) d \omega
$$

Various tests have been proposed to analyze the frequency domain nexus between two variables. In this study, we refer to Breitung and Candelon's (2006) study. They construct an F-test for the coefficients $\Theta(L)$ at different frequencies. To do so, the above equations (Equations (26) and (27)) should be re-written in matrix form:

$$
\Psi(L) v_{t}=\left(\begin{array}{l}
\psi_{11}(L) \psi_{12}(L) \\
\psi_{21}(L) \psi_{22}(L)
\end{array}\right)\left(\begin{array}{l}
X_{t} \\
Y_{t}
\end{array}\right)=\left(\begin{array}{l}
v_{1 t} \\
v_{2 t}
\end{array}\right)
$$

where $\psi_{11}(0)=1 ; \psi_{22}=1 ; \psi_{12}=0 ; \psi_{21}=0 ; \operatorname{cov}\left(v_{1 t}, v_{2 t}\right)=0 ; \Psi_{t}=[\Theta(L) G]^{-1} ; \quad G$ denotes the lower triangular matrix of the Cholesky decomposition; $v_{t}=G \xi_{t}$.

$$
\Gamma(L) \kappa_{t}=\left(\begin{array}{l}
\tau_{11}(L) \tau_{12}(L) \tau_{13}(L) \\
\tau_{21}(L) \tau_{22}(L) \tau_{13}(L) \\
\tau_{31}(L) \tau_{32}(L) \tau_{33}(L)
\end{array}\right)\left(\begin{array}{l}
X_{t} \\
Y_{t} \\
Z_{t}
\end{array}\right)=\left(\begin{array}{l}
\kappa_{1 t} \\
\kappa_{2 t} \\
\kappa_{3 t}
\end{array}\right)
$$

where $\tau_{11}(0)=1 ; \tau_{22}=1 ; \tau_{33}=1 ; \tau_{12}=0 ; \tau_{21}=0 ; \tau_{13}=0 ; \tau_{31}=0 ; \tau_{23}=0 ; \tau_{32}=0 ; \Gamma_{t}=[\Phi(L) G]^{-1} ; G$ denotes the lower triangular matrix of the Cholesky decomposition.

Ultimately, the null hypothesis of no Granger Causality at frequency $\omega$ can be written based on matrix notations (28) and (29) respectively as follows:

$$
\begin{aligned}
& H_{0}: R(\omega) \Theta(L)=0 \\
& H_{0}: R(\omega) \Phi(L)=0
\end{aligned}
$$

where $R(\omega)=\left[\begin{array}{l}\cos (\omega) \cos (2 \omega) \ldots \cos (p \omega) \\ \sin (\omega) \sin (2 \omega) \ldots \sin (p \omega)\end{array}\right]$

Throughout the rest of this research, we gauge empirically the nexus between oil price and Russian real exchange rate unconditionally and conditioning upon potential control variables. By doing so, we try to identify which technique among the above different methods is more suitable in this case and then to reach clearer and "one sided" relationship. 


\section{Results and discussions}

\subsection{ARDL findings}

We have converted all series into logarithm to lessen fluctuations in the data set. The results of descriptive statistics and correlation matrices are reported in Table- 1 containing log levels as well as returns. The sample mean of log of real effective exchange rate. Similarly, the sample mean of oil prices is positive and higher as compared to data for real effective exchange rate. Both variables of interest are positively correlated (Table-2). We clearly note that the skewness is negative for REER, gdp, gov, prod, while it is positive for Oil and te. This implies that the asymmetrical distribution is plausible for all series (except Oil and te). The Kurtosis is less important than 3 for all variables under consideration, meaning that their distributions are less flattened than the Gaussian ones.

Table-1: Descriptive Statistics

\begin{tabular}{|l|c|c|c|c|c|c|}
\hline & $\ln R E E R_{t}$ & $\ln$ Oil $_{t}$ & $\ln$ gdp $_{t}$ & $\ln$ gov $_{t}$ & $\ln t e_{t}$ & $\ln$ prod $_{t}$ \\
\hline Mean & 4.501413 & 5.176710 & 7.657595 & 5.867372 & -0.568013 & 3.915802 \\
\hline Median & 4.522875 & 5.014018 & 7.816417 & 5.953243 & -0.585051 & 3.864302 \\
\hline Maximum & 4.824306 & 6.524685 & 9.355912 & 7.593374 & -0.218863 & 5.660179 \\
\hline Minimum & 4.048301 & 4.181183 & 5.389072 & 3.583519 & -0.809386 & 2.063312 \\
\hline Std. Dev. & 0.214080 & 0.601103 & 1.132440 & 1.110010 & 0.140820 & 1.051965 \\
\hline Skewness & -0.528728 & 0.411982 & -0.279685 & -0.179176 & 0.379927 & -0.015771 \\
\hline Kurtosis & 2.445241 & 2.215188 & 1.868124 & 1.838564 & 2.621271 & 1.959960 \\
\hline Jarque-Bera & 3.505513 & 3.183161 & 3.918679 & 3.631819 & 1.771999 & 2.661586 \\
\hline Probability & 0.173296 & 0.203604 & 0.140952 & 0.162690 & 0.412302 & 0.264268 \\
\hline
\end{tabular}

Table-2: Correlations

\begin{tabular}{|l|c|c|c|c|c|c|}
\hline & $\ln R E E R_{t}$ & $\ln$ Oil $_{t}$ & $\ln g d p_{t}$ & $\ln$ gov $_{t}$ & $\ln t e_{t}$ & $\ln _{\text {prod }}$ \\
\hline $\ln$ REER $_{t}$ & 1 & & & & & \\
\hline $\ln$ Oil $_{t}$ & 0.6826637 & 1 & & & & \\
\hline $\ln$ gdp $_{t}$ & 0.5654454 & 0.8858752 & 1 & & & \\
\hline $\ln$ gov $_{t}$ & 0.6214614 & 0.8879732 & 0.99203015 & 1 & & \\
\hline $\ln t e_{t}$ & -0.2367291 & 0.13121513 & 0.24743089 & 0.18235737 & 1 & \\
\hline $\ln$ prod $_{t}$ & 0.7463875 & 0.88805956 & 0.85951042 & 0.88023320 & 0.07560403 & 1 \\
\hline
\end{tabular}


We have applied Ng-Perron (Ng-Perron, 2001) unit root test to examine whether the variables are stationary in the level form or first difference form. The obtained outcomes indicate that almost all considered variables show unit root behavior at level and found stationary at $1^{\text {st }}$ difference with intercept and trend (Table-3). The findings of Ng-Perron unit root tests may be biased due not having information about structural breaks stemming in the series. To solve this issue, we have applied de-trended Zivot and Andrews (1992)'s structural break unit test to examine the integrating orders of the variables in the presence of structural breaks.

We find from our results that real effective exchange rate is non-stationary at a level showing structural breaks in 1996q4. The variable of oil prices is stationary at level with structural break in 1998q2. Likewise, gdp, te and prod are stationary with respective breaks in 1997q4, 1996q4 and 1997q3, while gov seems non-stationary at level with structural break in 1999q1. These variables have mixed order of integration i.e., I(1)/I(0). This mixed order of integration of the variables leads us to apply the ARDL bounds testing approach to examine whether cointegration exists between the variables in the presence of structural breaks in the series.

Table-3: Unit Root Analysis

\begin{tabular}{|c|c|c|c|c|}
\hline \multirow[b]{2}{*}{ Variable } & \multicolumn{4}{|c|}{ Ng-Perron Unit Root Test } \\
\hline & MZa & MZt & MSB & MPT \\
\hline $\ln R E E R_{t}$ & $-13.0427(1)$ & -2.6547 & 0.2356 & 7.6548 \\
\hline $\ln \mathrm{Oil}_{t}$ & $-14.6219(1)$ & -2.6695 & 0.5790 & 6.5798 \\
\hline $\ln g d p_{t}$ & $-10.5872(1)$ & -3.0789 & 0.7619 & 6.5032 \\
\hline $\ln g o v_{t}$ & $-9.8391(2)$ & -4.1257 & 0.9281 & 7.0227 \\
\hline $\ln t e_{t}$ & $-13.1543(1)$ & -2.7614 & 0.6107 & 6.4269 \\
\hline \multirow[t]{2}{*}{ ln $\operatorname{prod}_{t}$} & $-10.3894(1)$ & -3.2611 & 0.5402 & 6.8355 \\
\hline & \multicolumn{2}{|c|}{ ZA at Level } & \multicolumn{2}{|c|}{ ZA at $1^{\text {st }}$ Difference } \\
\hline Variable & T-statistic & Time Break & T-statistic & Time Break \\
\hline $\ln R E E R_{t}$ & $-3.9192(2)$ & $1996 q 4$ & $-11.0602(1)^{*}$ & $1998 q 3$ \\
\hline $\ln \mathrm{Oil}_{t}$ & $-7.8351(4) *$ & $1998 q 2$ & $-7.8521(2)^{*}$ & 1999q1 \\
\hline $\ln g d p_{t}$ & $-4.5180(2)^{*}$ & $1997 q 4$ & $-3.9062(3)^{*}$ & $1998 q 1$ \\
\hline $\ln g o v_{t}$ & $-4.1253(1)$ & 1999q1 & $-3.6124(2)^{*}$ & 2001q2 \\
\hline $\ln t e_{t}$ & $-4.2269(2)^{*}$ & $1996 q 4$ & $-4.0021(1)^{*}$ & $1997 q 1$ \\
\hline $\ln$ prod $_{t}$ & $-5.3874(1)^{*}$ & $1997 q 3$ & $-5.1109(2)^{*}$ & 1999q1 \\
\hline
\end{tabular}

Note: * represent significant at 1 per cent level of significance. Lag order is shown in parenthesis. 
The appropriate lag order is a prerequisite to apply bounds testing to examine the long-run relationship between the variables. In doing, we chose Akaike information criteria (AIC) to select lag order of the variables (Table-4). It is suggested by Lütkepohl (2006) that we should apply AIC considered as the more appropriate method in choosing the lag length compared to sequential modified LR test statistic (LR), final prediction error (FPE); Schwarz information criterion (SIC) and Hannan-Quinn information criterion (HQ). When treating REER as dependent variable, the lag order 1 is chosen following the minimum value of AIC either unconditionally or conditionally on control variables ( $g d p$, gov, te and prod). However, when Oil is treated as dependent, the selected lag order is 2 unconditionally and 3 conditioning upon GDP, government revenues, terms of trade and productivity differential. We then calculated the ARDL F-statistic to decide whether cointegration exists between the real effective exchange rate and oil price.

Table-4: Lag Length Selection

\begin{tabular}{|c|c|c|c|c|c|c|}
\hline \multicolumn{7}{|c|}{ VAR Lag Order Selection Criteria } \\
\hline Lag & LogL & LR & FPE & $\mathrm{AIC}$ & SC & HQ \\
\hline \multicolumn{7}{|c|}{ (1): $F_{R E E R}\left(\ln R E E R_{t} / \ln O i l_{t}\right)$} \\
\hline 0 & 73.94200 & NA & 0.004603 & -2.543346 & -2.397358 & -2.486891 \\
\hline 1 & 77.02781 & 5.610559* & $0.004268 *$ & $-2.619193 *$ & $-2.436708 *$ & $-2.548625^{*}$ \\
\hline 2 & 77.21090 & 0.326228 & 0.004398 & -2.589487 & -2.370505 & -2.504805 \\
\hline 3 & 77.26023 & 0.086117 & 0.004556 & -2.554918 & -2.299439 & -2.456122 \\
\hline \multicolumn{7}{|c|}{ (2): $F_{\text {REER }}\left(\ln R E E R_{t} / \ln\right.$ Oil, ln gdp, ln gov, ln te, ln prod $)$} \\
\hline 0 & 68.16289 & NA & 0.005613 & -2.345770 & -2.122718 & -2.259995 \\
\hline 1 & 71.35393 & $5.539152 *$ & $0.005171^{*}$ & $-2.428450 *$ & $-2.168223 *$ & $-2.328379 *$ \\
\hline 2 & 71.48850 & 0.228529 & 0.005346 & -2.395793 & -2.098390 & -2.281426 \\
\hline 3 & 71.92033 & 0.716988 & 0.005468 & -2.374352 & -2.039774 & -2.245689 \\
\hline \multicolumn{7}{|c|}{ (3): $F_{\text {Oil }}\left(\ln \mathrm{Oil}_{t} / \ln R E E R_{t}\right)$} \\
\hline 0 & 23.82324 & NA & 0.028483 & -0.720845 & -0.574857 & -0.664390 \\
\hline 1 & 25.36429 & 2.801911 & 0.027934 & -0.740520 & -0.558035 & -0.669951 \\
\hline 2 & 29.39411 & 7.180403* & $0.025029 *$ & $-0.850695 *$ & $-0.631713 *$ & $-0.766013^{*}$ \\
\hline 3 & 29.63182 & 0.414911 & 0.025746 & -0.822975 & -0.567497 & -0.724180 \\
\hline \multicolumn{7}{|c|}{ (4): $F_{\text {Oil }}\left(\ln O i_{t} / \ln R E E R, \ln g d p, \ln\right.$ gov, $\ln t e, \ln$ prod $)$} \\
\hline 0 & 32.04563 & NA & 0.028448 & -0.728932 & -0.290968 & -0.559568 \\
\hline 1 & 36.34905 & $6.572487 *$ & 0.025278 & -0.849056 & -0.374596 & -0.665578 \\
\hline 2 & 38.43088 & 3.103833 & 0.024360 & -0.888396 & $-0.377438 *$ & -0.690804 \\
\hline 3 & 40.26022 & 2.660847 & $0.023700 *$ & $-0.918553 *$ & -0.371099 & $-0.706848 *$ \\
\hline
\end{tabular}

Notes: * indicates lag order selected by the criterion; LR: sequential modified LR test statistic (each test at 5\% level); FPE: Final prediction error; AIC: Akaike information criterion; SC: Schwarz information criterion. 
We have used the critical bounds generated by Pesaran et al. (2001). Our results reported in Table-5 reveal that the calculated ARDL F-statistic exceeds upper critical bound (UCB) i.e., $5.236>5.23$ at the 1 percent level once we treated real effective exchange rate as the dependent variable. We may reject the hypothesis of no cointegration and conclude that there is one cointegrating confirming a long-run relationship between real effective exchange rate and oil prices in the Russian economy during the period 1995q1-2009q3. When accounting for the above mentioned control variables, the results change slightly, reinforcing the above outcome. Accurately, we note that when the real exchange rate is treated as the dependent variable, the F-statistic exceeds UCB at the 1 percent level either unconditionally or conditionally to gdp, gov, te and prod. Nevertheless, the F-statistic seems less important than the lower critical bound (LCB) i.e., $2.189<2.97$ at the 10 percent level, indicating the absence of long-run cointegration. The consideration of further control variables has led to significant cointegration. In that case, we clearly find that the F-statistic exceeds upper critical bound (UCB) i.e. $4.391>4.23$ at the 5 percent level. Summing up, we can argue that bidirectional long term causality (i.e. cointegration) between oil price and Russia' real exchange rate is deeply supported when accounting for additional explanatory variables, while we only find a unidirectional interaction dynamic running from real exchange rate to oil price when neglecting the possible "pulling" effects of control variables in explaining the focal nexus. This link that runs from REER to Oil appears very logical, but the reverse relationship seems less intuitive.

This highlights the need of applying more parsimonious techniques on the one hand and of accounting for additional variables when investigating oil price-real exchange rate nexus on the other hand. While trying to confirm this assertion, we attempt in the following to compare between unconditional and conditional estimations via the use of "sophisticated" methods able to accurately capture nonlinearity in the focal causal connection (i.e., to analyze the relationship in question under different frequencies by applying wavelet coherency and frequency domain).

Table-5: The ARDL Bounds Testing Cointegration Analysis

\begin{tabular}{|l|c|c|c|c|}
\hline Estimated Model & $(1)$ & $(2)$ & $(3)$ & $(4)$ \\
\hline Optimal Lag Length & 3,3 & $3,3,1,2,0,1$ & 3,3 & $3,3,1,2,0,1$ \\
\hline Structural Break & $1996 q 2$ & $2001 q 2$ & $1998 q 1$ & $1999 q 4$ \\
\hline F-statistics & $5.236^{*}$ & $6.189^{*}$ & 2.189 & $4.391^{* *}$ \\
\hline Critical values & \multicolumn{2}{|c|}{ Upper Critical Bound } \\
\hline Lower Critical Bound & \multicolumn{2}{c|}{5.23} \\
\hline 1 per cent level & \multicolumn{2}{|c|}{4.30} & \multicolumn{2}{c|}{3.23} \\
\hline 5 per cent level & \multicolumn{2}{|c|}{3.38} & \multicolumn{2}{c|}{3.74} \\
\hline
\end{tabular}

Notes: (1): $F_{R E E R}\left(\ln R E E R_{t} / \ln O i l_{t}\right) ;(2): F_{\text {REER }}\left(\ln R E E R_{t} / \ln O i l, \ln g d p, \ln\right.$ gov, $\left.\ln t e, \ln p r o d\right) ;(3): F_{\text {Oil }}\left(\ln O i l_{t} / \ln R E E R_{t}\right)$; (4): $F_{\text {oil }}\left(\ln O i l_{t} / \ln R E E R_{t}, \ln g d p, \ln g o v, \ln t e, \ln\right.$ prod) $; *$, **, *** denotes the significance at $1 \%, 5 \%$ and $10 \%$ levels, respectively. The optimal lag structure is determined by AIC. Critical values bounds are from Pesaran et al. (2005). 


\subsection{Wavelet coherency findings}

The squared WTC of a return series of oil prices and real effective exchange rate is shown in Figure-3. From blue (low coherency) to red (high coherency), it seems difficult to make sense of the picture that depicts the interdependence between REER and Oil (the upper left graph, Figure-3). Regions of high frequency are very scarce. This is particularly evident when we focus on the period spanning between 2003 and 2005. This implies that there are significant regions where the interdependence between the two variables seems stronger and other time-frequency spaces where the co-movement between series appears sharply unclear. When looking at the phase-difference, we worthy note that the real exchange rate and oil price move together at a specified frequency band since the phase relationship appears situated between $-\pi / 2$ and 0 . In that case, REER is lagging. The 5 -quarter cycles are in phase from 1995q1 to 2009q3, except the period spanning between 2003q4 to 2004 q3 (the blue line in the lower left graph, Figure-3). This implies that for almost all the period under consideration, the focal variables seem positively correlated, while the studied connection appears negative in 2004. In that period, there is an anti-phase relationship between the two variable where oil price is leading (the phase difference is between $-\pi$ and $\pi / 2$. This observation may be owing to the adoption of less restrictive capital control regulations, making a switch from an authorization-based system to flow control, leading to a steady upward pressure on the ruble. Nevertheless, when additional variables are controlled for, the relationship between the two key series changes remarkably (the blue line in the lower right graph, Figure-3). We clearly show that the real exchange rate and oil price move together conditioning upon GDP, governmental expenditure revenues, terms of trade and the productivity differential of welldefined frequency. Indeed, the phase difference is situated between $-\pi / 2$ and 0 , at which the Russia's real exchange rate is lagging. The 6-quarter cycles are in phase between 1995q1 and 2009q3, whereas there is an anti-phase linkage between key variables and the additional control series from 1998q4 to 2001q4 (the blue line in the lower right graph, Figure-3). This means that REER is positively correlated with Oil conditionally on potential control variables, while this interdependence becomes clearly negative from 1998 to 2001. During that period, the phase difference is between $-\pi$ and $\pi / 2$ and therefore there is a conditional anti-phase nexus where oil price is leading. We cannot attribute this last outcome to specific factors since Russia has experienced several purifying events in this period; For instance, the violent inflation, the Asian crisis and thus the drop in external demand (Asia is one of the main trade partners of Russia) and the positive boost from increasing energy prices. In addition, on the upper right graph, we can see that there are regions of high coherency between 1998 and 2009. More precisely, there is a noticeable interaction dynamic between REER and Oil conditional on GDP, governmental revenues, terms of trade and productivity differential. Unsurprisingly, the studied period (in particular from 1998 to 2009) was marked by failing stabilization and disappointing macroeconomic performance and the aftermath of the current economic crisis that may affect widely the external energy demand, especially when considering that Europe seems a potential trading partner of Russia ${ }^{3}$. The fiscal policy within

\footnotetext{
3 For details about the trade partners of Russia, see the Observatory of Economic Complexity : $\underline{\text { http://atlas.media.mit.edu/country/rus/ }}$
} 
the Putin administration framework aiming at changing oil price elasticities of revenues and expenditures to avoid the possible harmful effects of sudden disturbances, speculative attacks and negative oil shocks (Merlevede et al. 2009) may be also advanced as a possible explanation of these observations.

Importantly, the conditional continuous wavelet transform approach has allowed us to highlight the time scale interdependence between the real exchange rate and oil price. This seems highly difficult when not accounting for control variables. It is also hard to capture proper nexus between the considered series at specified time horizons with conventional methods as ARDL bounds testing approach.

\section{Figure-3: Conditional vs unconditional wavelet coherency: The REER-Oil nexus}
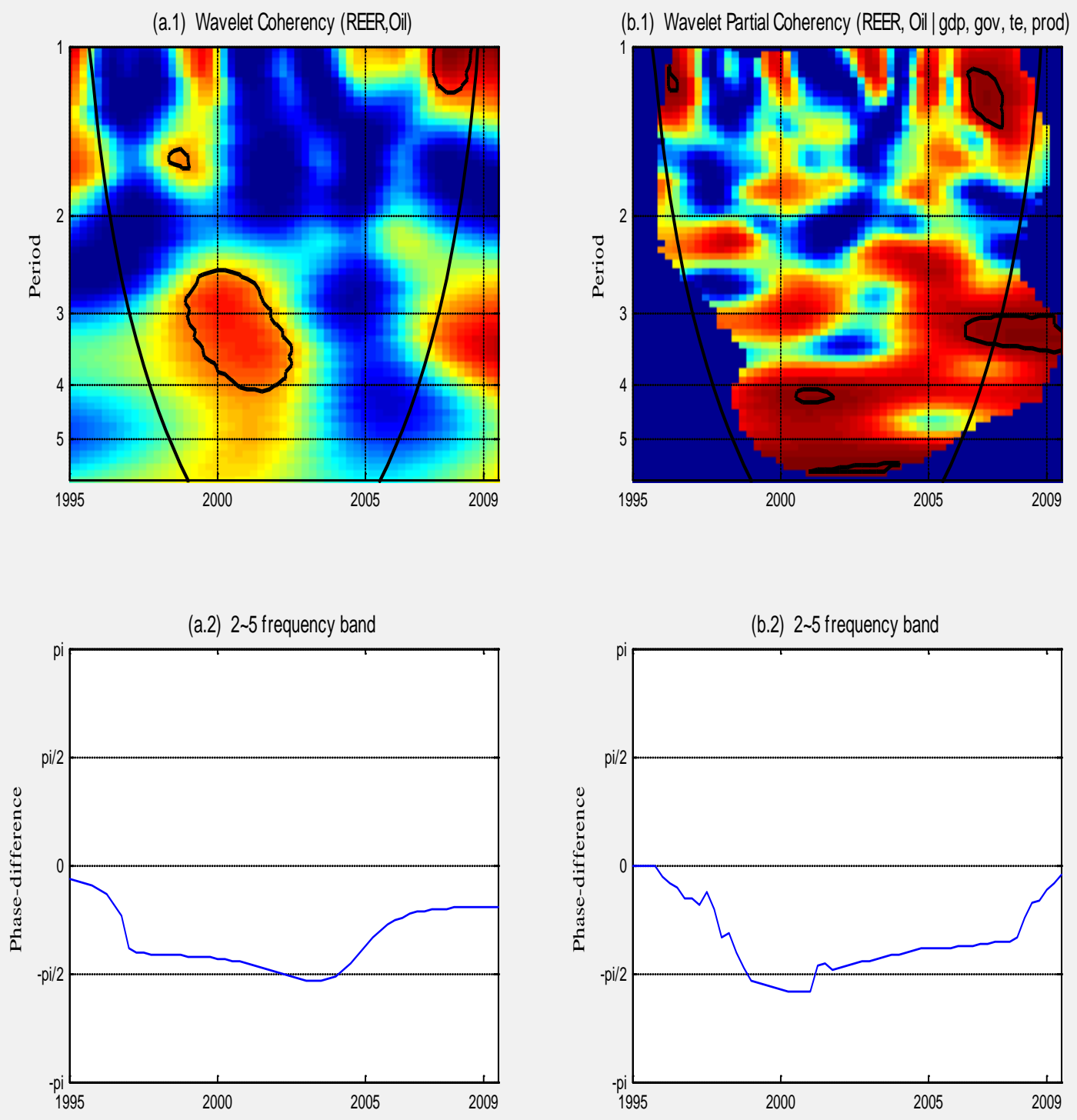

Notes: The thick black contour designates the $5 \%$ significance level against red noise which is estimated from Monte Carlo simulations using phase randomized surrogate series. The cone of influence, which indicates the region affected by edge effects, is also shown with a light black line. The color code for coherency ranges from blue (low coherency) to red (high coherency). 


\subsection{Frequency domain findings}

Figure-4 depicts the nexus between oil price and the real exchange rate. It is well shown that Oil Granger-cause BPI in the lower frequencies (i.e. long-run time scale) or more precisely when $\omega \in[0.01 \pi-0.44 \pi]$. The reverse link is not supported at any frequency. These outcomes change when considering the aforementioned control variables. More precisely, we find that the causal relationship running from Oil to REER stills significant at low frequency band but not in large frequency or accurately $\omega \in[0.01 \pi-0.76 \pi]$. This outcome may be due to the fact that the energy market is a large market relative to other commodities and the assumption of financial speculation may be evident. The demand and supply shocks in the global oil market often entailed offsetting changes in oil inventories to reinforce oil price instability that may affect intensely real exchange rate in low frequency bands through differential price (Alquist and Kilian (2010) and Bouoiyour and Selmi (2014 c)). Furthermore, we should mention that only the interaction dynamic that runs from oil price to real exchange rate changes among the different frequencies involved. The reverse interconnection remains insignificant. This implies that Russia should take proper attention to disturbances, mainly caused by oil price and continue to decrease its oil dependency. Thus, there is a great need of solid fiscal, economic and political measures to appropriately avoid external shocks, mitigate oil dependency and then create the confidence needed for economic recovery.

Interestingly, wavelet coherency and frequency domain via Breitung and Candelon's (2006) method seems more suitable to properly test the dynamic between oil price and Russian real exchange rate than ARDL Bounds testing approach. Unsurprisingly, the last technique seems unable to detect whether the strength of co-movement changes substantially within the time scales over the period in question and if there are some differences with respect to the focal nexus among the different frequencies involved. Beyond this computational comparison, the observed outcomes are rather substitutable than complementary. ARDL outcomes and those of wavelet coherency appear heavily different. More precisely, bidirectional long term causality is supported when using ARDL, while a unidirectional connection is sharply observed when carrying out wavelet method and frequency domain analysis. These new methods seem more intuitive. It is noted that conventional and "sophisticated methods" show the utmost importance to add control variables when assessing the connection between our variables of interest (Oil and REER). With special reference to Russian case, oil price cannot always be regarded as a significant contributor of changes in real exchange rate, since it has only a significant effect on lower frequencies, conditioning upon to GDP, governmental expenditure revenues, terms of trade and productivity differential. This, partially, highlights the effectiveness of fiscal policy within the Putin administration framework aiming at changing oil price elasticities of revenues and expenditures (Merlevede et al. 2009) to avoid the possible harmful effects of excessive oil price fluctuations on the whole economy. But an effective risk management strategy should be able to better cope with oil shocks, to avoid short-run disturbances and to mitigate the detrimental effects of excessive ups and downs of oil price on real exchange rate. This should seriously be consolidated through the development of effective counter-cyclical fiscal policy and compensatory financial system. 
Figure-4: Conditional vs unconditional frequency domain: The REER-Oil nexus

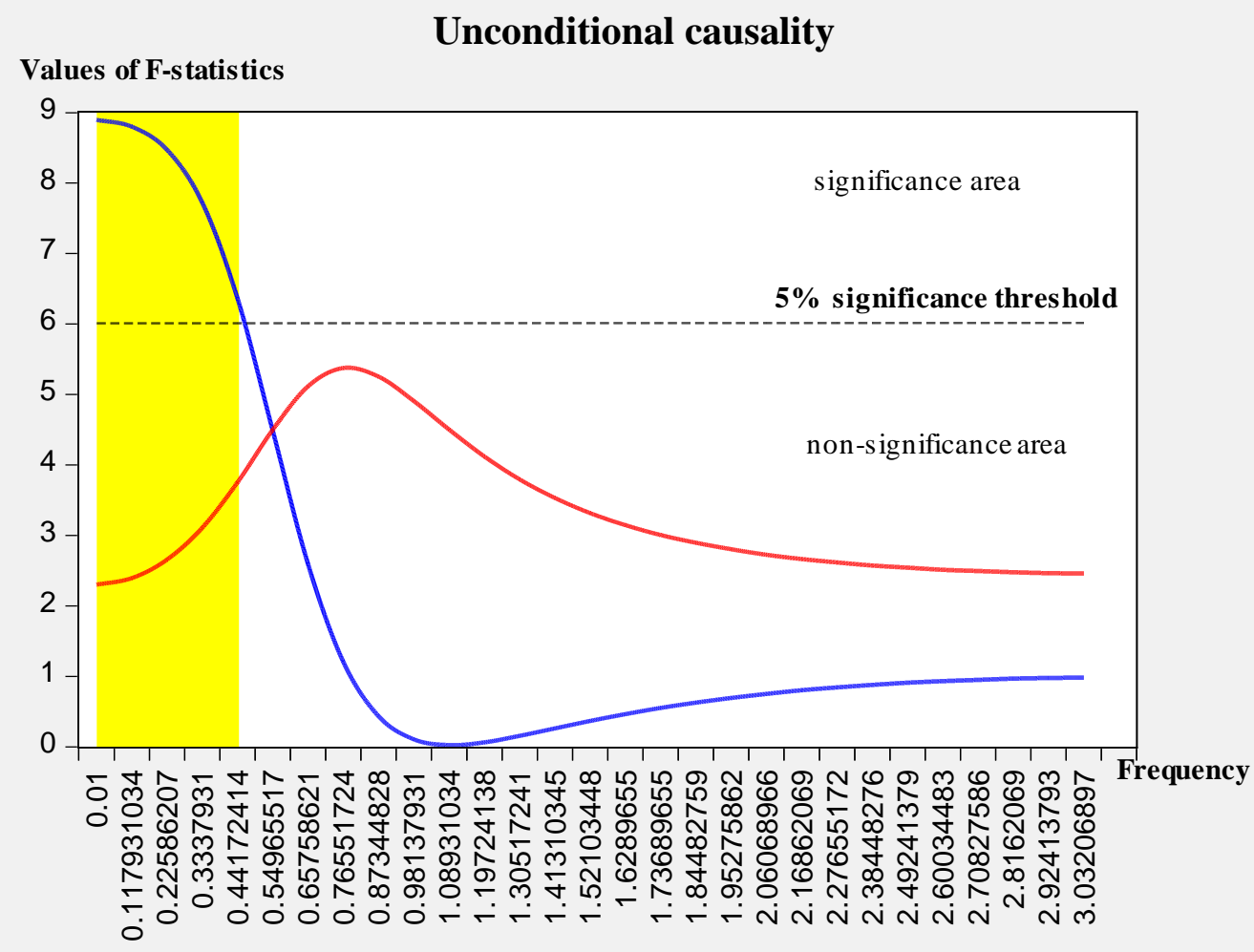

- Oil does not Granger-cause REER

REER does not Granger-cause RER

----- BC critical values

\section{Values of F-statistics \\ Conditional causality}

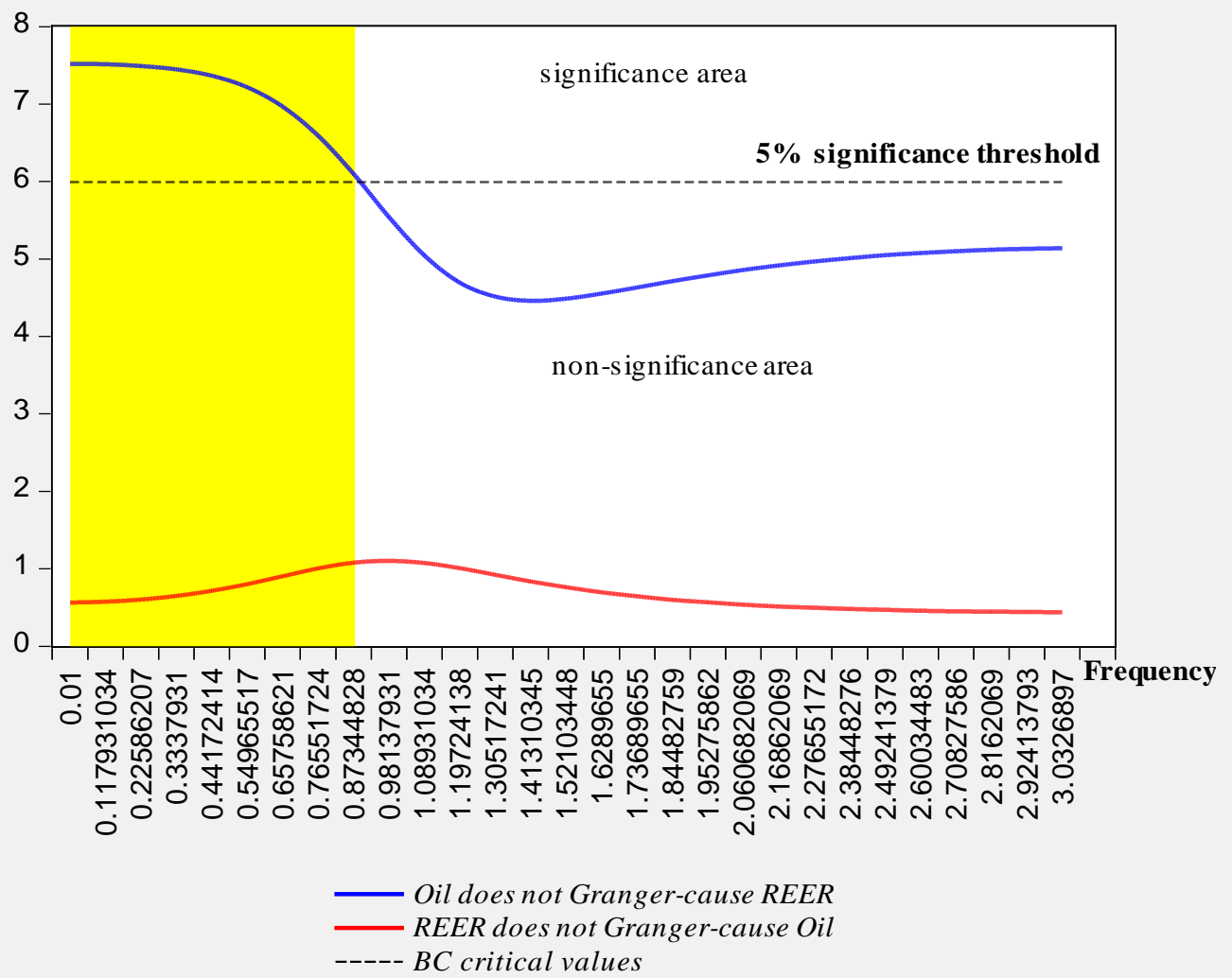




\section{Concluding Remarks and Policy Implications}

This research contributes to the existing literature on the oil price-real exchange rate nexus by assessing the long-run cointegration, the interdependence and the lead-lag relationship unconditionally and conditionally to GDP, governmental revenues, terms of trade and productivity differential. To this end, we decompose the connection between these variables into short-run and long-run relationships (ARDL bounds testing approach), among different time scales (wavelet coherency) and into various frequency components (frequency domain through Breitung and Candelon's (2006) method). Our findings provide insightful evidences that may be summarized as follows:

(i) Using ARDL bounds testing approach, we show a long-run cointegration between oil price and real exchange rate conditionally to the additional control variables either when treating Oil or REER as dependent variables.

(ii) By applying wavelet coherency, we observe a significant and meaningful nexus between variables in regions of high coherency. This outcome is likely to be observed when following conditional analysis rather than unconditional evaluation. Russia's real exchange rate is lagging. The studied nexus seems in phase for almost all the period, while there is an anti-phase connection between the two focal variables and the additional time series from 1998 to 2001 where oil price is leading. Indeed, REER is positively correlated with Oil conditionally on control variables, while this interdependence becomes clearly negative from 1998 to 2001. During that period, the phase difference is between $-\pi$ and $\pi / 2$ and therefore there is a conditional anti-phase nexus.

(iii) By carrying out Breitung and Candelon's (2006) approach, there is a causal relationship that runs from oil price to real exchange rate in lower frequencies. The reverse link is not supported. The oil price cannot always be regarded as a potential contributor, since it has only a significant effect on REER in lower frequencies, conditioning upon to potential control variables.

(iv) The followed methods are likely to be substituted rather than complementary. However, the use of econometric techniques that take into account frequency transformations appear more useful and intuitive. They all reveal the importance to consider nonlinearity and control variables when investigating oil price-real exchange rate relationship. Indeed, the wavelet coherency and the frequency domain technique appear more suitable and fruitful than ARDL bounds testing approach since they depict the nexus in question at well defined time-scales and specified-frequencies, respectively. At this stage, we can say that the lack of studies reaching robust nexus and conclusive results about how behave real exchange rate after the sizeable volatility of oil prices and vice versa may be mainly due to (1) the neglect of control variables that play a potential role in explaining the connection between the two key variables in the majority of works, and to (2) the ineffectiveness or the inadequacy of models used to properly depict this linkage. This research puts in evidence that the consideration of nonlinearity (time scale or frequency decomposition) is needed in the focal issue. 
The observed outcomes may have important implications for Russian policymakers, practitioners and advisors on exchange and energy markets.

The significant causal link running from oil price to real exchange rate highlight the need to diversify their products to cope with cyclicality of prices and speculation, without focusing on massive Bank currency interventions in the face of an oil price shock as they will most likely to fail (Bouoiyour and Selmi, 2014 c). This energy exporting country should tackle appropriately with excessive oil price fluctuations, especially because these prices are triggered by the interplay between supply and unstable demand. The external demand itself seems to be generated by cyclicality of international commodity prices and seasonality. This country should also continue the policy reform towards weaker energy dependency. To be able to act appropriately to oil shocks, the Central bank of Russia should implement efficient monetary policy tools (i.e., robust banking system, deep financial markets and effective institutional quality) and improve the role of interest rates to effectively control the exchange market and inflation dynamics and then to better cope with sudden shocks and disturbances.

More importantly, a more flexible exchange rate would better absorb external shocks. This may be reinforced by a policy in favor of a focus on inflation target in order to counterbalance the sizable exchange rate instability. Intuitively, policy makers should be aware that the connection between oil price and the real exchange rate depends on different time scales and the frequencies involved. Since there is a causal link running from Oil to $R E E R$ and not vice versa unconditionally and conditionally to appropriate variables (GDP, governmental revenues, terms of trade and productivity differential), a considerable increase in oil price may rise heavily federal revenues. This may delay reforms implemented to diversify exports and trade partner destinations and to lessen the great oil dependency.

Beyond our results and if we look more closely at the current situation in Russia, we can say that this economy faces several challenges including the heavily drop in external demand that may have substantial influence on the evolution of commodity prices, public finances and trade performance without forgetting the unpleasant economic sanctions against Russia because of its support for Ukrainian independentists. The economic and fiscal initiatives of Putin administration may help to better cope with shocks and to mitigate the dependence on energy sector, since we believe that Russia is aware of the very prime importance of diversification (in terms of products or sectors and trade destinations) to overcome the possible detrimental effects of the decrease in external demand and the cyclical behavior of international commodity prices.

While our research does not say much about the routes through which oil price may affect differently the real exchange rate, it clearly indicates the presence of short-term nexus conditioning upon potential control variables. The substantial question here is whether we can affirm that Russian monetary authorities have won a first round. The real exchange rate depends significantly to oil price fluctuations, but this link in only valuable in the short-run. The drastic and appropriate efforts pursued by Russian authorities have allowed to reach a progressive connection between both focal variables. It remains now a second round to be won by the acceleration of deeper structural reforms to mitigate the dependence of the 
Russian economy on oil price movements. This needs an impactful strategic development via an increase of investment in human capital, an improvement of innovative capacity and a fight against government corruption. 


\section{References}

Akram, F.Q. (2004), “Oil wealth and real exchange rates : The FEER of Norway.” Working paper of Money, Macro and Finance Research Group n 33.

Aguiar-Conraria L, Azevedo N. and Soares M-J. (2008), Using wavelets to decompose the time- frequency effects of monetary policy. Phyisca, 387, pp. 2863-2878.

Aguiar-Conraria, L. and Soares, M-J. (2011), Oil and the macroeconomy: using wavelets to analyze old issues. Empirical Economics, 40, pp. 645-655.

Albulescu, C.T., Oros, C. and Tiwari, A.K. (2013), "Revisiting the inflation-output gap relationship for France using a wavelet transform approach.” $30^{\text {th }}$ International Symposium on Money, Banking and Finance, University of Poitiers, France.

Alquist R. and Kilian L. (2010), "What do we learn from the price of crude oil futures?” Journal of Applied Econometrics 25, pp. 539-573.

Amano, R. and van Norden, R. (1998), “Exchange rates and oil prices.” Review of International Economics 6(4), pp. 683-694.

Antczak, R., (2001), “The Russian financial crisis of 1998.” In M. D'browski (ed.), The Episodes of Currency Crises in Transition Economies, CASE Reports 40, Warsaw.

Beck, R. and Barnard, G. (2009), “Towards a Flexible Exchange Rate Policy in Russia.” OECD Economics Department Working Papers n 744.

Benhmad, F. (2012), "Modelling nonlinear Granger causality between the oil price and US dollar: A wavelet approach.” Economic modelling, 29, pp. 1505-1514.

Bénassy-Quéré, A., Mignon, V., Penot, A. (2007), China and the relationship between the oil price and the dollar. Energy Policy 35, pp. 5795-5805.

Bouoiyour, J. and Selmi, R. (2014 a), “GCC Countries and the Nexus between Exchange Rate and Oil Price: What wavelet decomposition reveals?" International Journal of Computational Economics and Econometrics, Forthcoming.

Bouoiyour, J. and Selmi, R. (2014 b), "Commodity price uncertainty and manufactured exports in Morocco and Tunisia: Some insights from a novel GARCH model." Economics Bulletin, 34(1), pp. 220-233.

Bouoiyour, J. and Selmi, R. (2014 c), “Exchange Rate Impact on Russia’s Exports: Some evidence from an evolutionary co-spectral analysis.” Working paper, University of Pau.

Breitung, J., and Candelon, B. (2006), “Testing for short and long-run causality: a frequency domain approach.” Journal of Econometrics, 132, pp. 363-378.

Cashin, P., Céspedes, F. and Sahay, R. (2004), “Commodity currencies and the real exchange rate”. Journal of Development Economics, 75, pp. 239-268. 
Camarero, M. and Tamarit, C. (2002), "Oil prices and Spanish competitiveness: A cointegrated panel analysis.” Journal of Policy Modeling, 24(6), pp. 591-605.

Chen, Y.-C. and K. Rogoff (2003), “Commodity Currencies”. Journal of International Economics, 60, pp. 133-160.

Chen, S., Chen, H. (2007), Oil prices and real exchange rates. Energy Economics, 29, pp. 390-404.

Corden, W. M. and J.P. Neary (1982), "Booming sector and de-industrialisation in a small open economy”. Economic Journal, 92, pp. 825-848.

Coudert, V., Mignon, V. and Penot, A. (2008), “Oil Price and the Dollar.” Energy Studies Review, 15(2), pp. 45-58.

Dibooglu, S., (1996), "Real disturbances, relative prices and purchasing power parity. Journal of Macroeconomics 18(1), pp. 69-87.

Égert, B. (2005), “Equilibrium Exchange Rates in Southeastern Europe, Russia, Ukraine and Turkey: Healthy or (Dutch) Diseased?" William Davidson Institute Working Paper $\mathrm{n}^{\circ}$ 770, William Davidson Institute at the University of Michigan.

Faria J-R., Mollick A-V, Albuquerque, P-H. and Leon-Ledesma, M-A. (2009), "The effect of oil price on China’s exports.” China Economic Review, 20, pp. 793-805.

Ghosh, S. (2011), Examining crude oil price - Exchange rate nexus for India during the period of extreme oil price volatility. Applied Energy, 88(5), pp.1886-1889.

Galkovskaya, V. (2011), "Does nominal exchange rate have a predictive power for oil and gas prices?” The case of Russia. Research Paper 62. http://opensiuc.lib.siu.edu/gs_rp/62

Geweke, J. (1982), "Measurement of linear dependence and feedback between multiple time series.” Journal of American Statistical Association, 77, pp. 304-324.

Granger, C.W.J. (1969), "Investigation causal relations by econometric models and crossspectral methods.” Econometrica, 37, pp. 424-438.

Granville, B. and Mallick, S. (2006), “Does inflation or currency depreciation drive monetary policy in Russia?” Research in International Business and Finance, 20, pp. 163-170.

Krugman, P. (1983), “Oil shocks and exchange rate dynamics.” in Frankel, J.A. (ed), Exchange rates and international macroeconomics, University of Chicago Press.

Lizardo, R-A. and Mollick, A-V. (2010), "Oil price fluctuations and U.S. dollar exchange rates.” Energy Economics, 32, pp. 399-408.

Lütkepohl, H. (2006), “Structural vector autoregressive analysis for cointegrated variables.” AStA Advances in Statistical Analysis, 90, pp. 75-88. 
MacDonald, R. (1998), "What determines real exchange rates? The long and the short of it," Journal of International Financial Markets, Institutions and Money, 8, pp. 117-153.

Meese, R. and Rogoff, K.S. (1988). "Was it real? the exchange rate-interest differential relation over the modern floating-rate period.” Journal of Finance, 43 (4), pp. 933-948.

Merlevede, B., Schoors, K. and van Aarle, B. (2009), "Russia From Bust to Boom and back: Oil Price, Dutch Disease and Stabilisation Fund.” Comparative Economic Studies, 51, pp. 213-241.

Mansor, H.I. (2011), “Oil Price and Real Effective Exchange Rate In A Small Oil-Exporting Country: A Recursive-Rolling View.” The 2011 Las Vegas International Academic Conference.

Naccache, T. (2011), “Oil price cycles and wavelets.” Energy Economics, 33, pp. 338-352

Narayan, P-R., Narayan, S., Prasad, A. (2008), Understanding the oil price - exchange rate nexus for the Fiji islands. Energy Economics, 30, pp. 2686-2696.

Ng, S. and Perron, P. (2001), "Lag Length Selection and the Construction of Unit Root Tests with Good Size and Power.” Econometrica, 69(6), pp. 1519-1554.

Pesaran M-H., Shin Y. and Smith, R-J. (2001), "Bounds testing approaches to the analysis of level relationships.” Journal of Applied Econometrics, 16, pp. 289-326.

Rautava, J. (2004), "The role of oil prices and the real exchange rate in Russia's economy cointegration approach.” Journal of Comparative Economics 32, pp. 315-327.

Raymond, J. and Rich, R.W. (1997), “Oil and the Macroeconomy: A Markov State-Switching Approach,” Journal of Money, Credit and Banking, 29(2), pp. 193-213.

Reboredo, J. (2012), “Modelling oil prices and exchange rate co-movements.” Journal of Policy Modelling, 34, pp. 419-440.

Sadorsky P. (2000), "The empirical relationship between energy futures prices and exchange rates.” Energy Economics, 22, pp. 253-266.

Selmi, R., Bouoiyour, J. and Ayachi, F. (2012), “Another look at the interaction between oil price and exchange rate: Case of small open economies.” Procedia Economics and Finance, 1, pp. 346-355.

Shahbaz, M., Tiwari, A-K. and Tahir, M-I. (2013), “Analyzing Time-Frequency Relationship between Oil Price and Exchange Rate in Pakistan through Wavelets.” MPRA paper $n^{\circ}$ 48086, July.

Tiwari, A-K., Dar, A-B. and Bhanja, N. (2013), "Oil price and exchange rates: a wavelet based analysis for India.” Economic Modelling, 31, pp. 414-422. 
Tokarick, S. (2008), “Commodity currencies and the real exchange rate.” Economic Letters, 101, pp. 60-62.

Torrence C. and Compo G.P. (1998), “A practical guide to wavelet analysis.” Bulletin of the American Meteorological Society, 79, pp. 605-618.

Zhang Y-J, Fan Y, Tsai H-T. and Wei Y-M (2008), "Spillover effect of US dollar exchange rate on oil prices.” Journal of Policy Modeling, 30, pp. 973-991.

Zhou, Su. (1995), The response of real exchange rates to various economic shocks. Southern Economic Journal, 61 (4), pp. 936-995.

Zivot E. and Andrews, D. (1992), "Further evidence of great crash, the oil price shock and unit root hypothesis.” Journal of Business and Economic Statistics, 10, pp. 251-270. 